\title{
VISUALIZAÇÃO DE INFORMAÇÃo PARA SIMPLIFICAR O ENTENDIMENTO DE INDICADORES SOBRE AVALIAÇÃO DA CIÊNCIA E TECNOLOGIA
}

\author{
INFORMATION VISUALIZATION TO SIMPLIFY UNDERSTANDING INDICATORS FOR \\ EVALUATION OF SCIENCE AND TECHNOLOGY
}

\begin{abstract}
VISUALIZACIÓN DE LA INFORMACIÓN PARA SIMPLIFICAR INDICADORES DE
\end{abstract} ENTENDIMIENTO PARA LA EVALUACIÓN DE LA CIENCIA Y LA TECNOLOGÍA

${ }^{1}$ Mirian Clavico Alves, ${ }^{2}$ Leandro Innocentini Lopes de Faria, ${ }^{2}$ Roniberto Morato do Amaral Universidade Estadual de Campinas, ${ }^{2}$ Universidade Federal de São Carlos

\section{Correspondência}

${ }^{1}$ Mirian Clavico Alves.

Universidade Estadual de Campinas

Campinas, SP

Email: mirianaq@gmail.com

ORCID: http://orcid.org/0000-0001-9098-

$\underline{0062}$

Submetido em: $16-08-2016$

Aceito em: 19-03-2017

Publicado: 12-04-2017

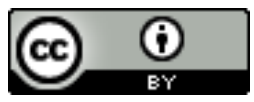

JITA: BB. Bibliometric methods

\begin{tabular}{|l|l|l|l|l|l}
\hline (C) RDBCI: Rev. Digit. Bibliotecon. Cienc. Inf. & Campinas, SP & v.15 & n.2 & p.324-348 & maio/ago. 2017 \\
\hline
\end{tabular}


RESUMO: O crescimento da atividade científica e o desenvolvimento de novas tecnologias voltadas para a divulgação do conhecimento contribuíram para a geração de diversos indicadores, muito utilizados como instrumentos de avaliação da ciência e tecnologia. O Brasil estabeleceu uma infraestrutura própria para avaliar a atividade científica do país e, mais especificamente, da Pós-Graduação, liderada pela Coordenação de Aperfeiçoamento de Nível Superior (Capes), que faz uso de indicadores no seu processo de avaliação disponíveis para acesso público. Visando facilitar a compreensão dos indicadores científicos, o objetivo geral desta pesquisa foi elaborar e analisar um conjunto de indicadores científicos, com base na área da visualização de informação. Como método de pesquisa foi utilizado o estudo de caso e a unidade caso foram nove Programas de PósGraduação da área de Economia avaliados pelo Sistema de Avaliação da Capes no triênio de 2013. Os resultados alcançados constituírem-se em um conjunto de indicadores sobre as dimensões do Sistema de Avaliação da Capes. Com base no referencial teórico e na discussão dos resultados alcançados, concluiu-se que é viável utilizar os conceitos da área de visualização de informação para facilitar a compreensão das dinâmicas da ciência, em especial sobre a atuação dos PPG, com a elaboração de indicadores a partir dos dados e informações disponibilizados pelo Sistema de Avaliação da Capes, auxiliando os tomadores de decisão a respeito da implementação de políticas públicas e na gestão dos PPG.

PalavraS-Chave: Bibliometria. Indicadores científicos. Visualização de informação. Coordenação do Aperfeiçoamento de Pessoal de Nível Superior. Pós-Graduação. Ciências Econômicas.

ABSTRACT: The growth of scientific activity and the development of new technologies for the dissemination of knowledge contributed to generate various indicators, used as evaluation tools of science. In addition, Brazil has established its own infrastructure to assess the scientific activity in the country and more specifically, the graduate courses, led by the Coordination of Superior Level Staff Improvement (CAPES), which makes use of indicators in the evaluation process of such courses, which are available for public access. In order to enhance the understanding of scientific indicators, the overall goal of this research was to develop and analyze a set of scientific indicators, based on the information visualization area. The chosen research method was a case study that contemplates nine graduate program in the economics area. The data was extracted from the CAPES evaluation system report from the 2013 triennial. The results achieved are a set of indicators on the dimensions of the Capes Evaluation System. Based on the theoretical background as well as the discussion of the obtained results, the conclusion is that it is feasible to make use of the concepts of information visualization area to enhance the understanding of the dynamism of science, in particular the performance of graduate programs, through the development of indicators based on data and information provided by the CAPES evaluation system, helping decision makers in the implementation of public policies and the management of such programs.

KEYWORDS: Bibliometrics. Scientific indicators. Information Visualization. Coordination of Superior Level Staff Improvement - Capes. Graduate-Brazil. Economics Sciences.

RESUMEN: El crecimiento de la actividad científica y el desarrollo de nuevas tecnologías para la difusión del conocimiento han contribuido a la generación de diversos indicadores, hoy en día ampliamente utilizados como herramientas de evaluación de la ciencia. Junto a esto, Brasil estableció su propia infraestructura para evaluar la ciencia de la actividad país y, más específicamente, el posgraduación, dirigido por la Coordinación de Mejora de Personal de Nivel Superior (CAPES), que hace uso de indicadores en el proceso de evaluación, disponible para el acceso público. Para facilitar la comprensión de los indicadores científicos, el objetivo general de esta investigación fue desarrollar y analizar un conjunto de indicadores científicos, basada en el área de visualización de la información. Como método de investigación utilizado fue el estudio de caso y la unidad de estudio de casos fueron nueve Programas de Postgrado de la área de Economía evaluados por el Sistema de Evaluación Capes en el 2013 trienal. Los resultados obtenidos son un conjunto de indicadores de las dimensiones del Sistema de Evaluación de la Capes. Con base en el marco teórico y discusión de los resultados obtenidos, se concluye que es factible hacer uso de los conceptos de área de visualización de la información para facilitar la comprensión de la dinámica de la ciencia, en particular, sobre el papel de los PPG de mediante el desarrollo de indicadores basados en los datos y la información proporcionada por el Sistema de Evaluación de la Capes, para ayudar a los tomadores de decisiones en cuanto a la implementación de políticas públicas y la gestión de PPG.

PAlabras ClaVE: Bibliometría. Indicadores Científicos. Visualización de información. Coordinación de Mejora de Personal de Nivel Superior. Posgraduación. Ciencias Económicas.

\begin{tabular}{l|l|l|l|l|l}
\hline (C) RDBCI: Rev. Digit. Bibliotecon. Cienc. Inf. & Campinas, SP & v.15 & n.2 & p. 324-348 & maio/ago. 2017 \\
\hline
\end{tabular}




\section{INTRODUÇÃ̃o}

A pesquisa científica apresenta significativo impacto no desenvolvimento social e econômico dos países. É pela ciência que o homem busca conhecer o mundo e encontrar as respostas para inúmeras situações e fenômenos (DORTA-GONZÁLEZ, 2010). No Brasil, as universidades públicas têm sido o local de concentração dos pesquisadores e esses têm contribuído para a expansão dos cursos de pós-graduação stricto-sensu ${ }^{1}$, responsáveis pela maior parte da produção científica brasileira e seu crescimento qualitativo e quantitativo nos últimos 40 anos (DANTAS, 2004).

A atividade de pesquisa consome somas consideráveis de recursos públicos e privados, razão pela qual é importante analisar os resultados que gera, assim como seu impacto em diferentes dimensões - científica, ambiental, econômica e social (DAVYT; VELHO, 2000; ZACKIEWICZ, 2003; BAUMGARTEN, 2004; DORTA-GONZÁLEZ, 2010). Uma das formas para medir a ciência é a elaboração de indicadores sobre a produção científica e tecnológica, a partir de estudos métricos da ciência (OKUBO, 1997; GREGOLIN et al, 2004; LIBERAL, 2005; FARIA et al., 2011). O Brasil estabeleceu uma infraestrutura própria para a avaliação da ciência, em especial dos resultados alcançados pelos Programas de Pós-Graduação (PPG), conduzida pela Coordenação de Aperfeiçoamento de Pessoal de Nível Superior (CAPES), que compreende uma engenhosa combinação de elementos, envolvendo a avaliação por pares e a coleta de dados sistemáticos sobre o desempenho dos PPG, como quantidade e qualidade das publicações, qualificação do quadro docente, número de alunos entre outros (SCHWARTZMAN, 2013).

O crescimento da produção científica, somado ao desenvolvimento de tecnologias para a divulgação dos resultados da ciência, contribuiu para o aumento do volume de dados e informações disponibilizados à sociedade sobre o resultado, por exemplo, das atividades de pesquisa desempenhadas pelos PPG. Pelo Sistema de Avaliação Capes $^{2}$ é possível acessar uma diversidade de documentos, dentre eles os Cadernos de Indicadores e Planilhas de Indicadores. Porém, a dificuldade de compreensão das informações contidas nesses documentos, que apesar de estarem disponíveis para acesso público e em diversos formatos, devido ao volume, organização e apresentação dessas informações, dificultam a realização de análises sobre o desempenho dos PPG pela sociedade, e, em especial, pelos tomadores de decisão.

O excesso de informações e o estudo de como representá-las através de uma forma visual, buscando facilitar a sua compreensão, tem sido uma das principais preocupações dos

\footnotetext{
${ }^{1}$ São considerados Programas de Pós-Graduação stricto-sensu "programas de mestrado e doutorado abertos a candidatos diplomados em cursos superiores de graduação", e que estão "sujeitos às exigências de autorização, reconhecimento e renovação de reconhecimento prevista na legislação - Resolução CNE/CES n 1/2001, alterada pela Resolução CNE/CES no 24/2002” (MEC, 2016, p. 01).

${ }^{2}$ http://www.capes.gov.br/avaliacao
} 
estudos da área de visualização de informação, que compreende a investigação das principais formas de representações gráficas para apresentação de informações, com o intuito de contribuir para o entendimento delas, além de ajudar na percepção dos indivíduos a fim de deduzir novos conhecimentos baseados no que está sendo apresentado (FREITAS et al., 2001).

Organizar dados e informações sobre a ciência e tecnologia na forma de indicadores com base nos conceitos da área de visualização de informação, pode contribuir para maximizar a compreensão dos resultados das iniciativas científicas e tecnológicas em que os pesquisadores brasileiros estão envolvidos, e ainda, nortear decisões referentes ao desenvolvimento e implementação de políticas de ciência e tecnologia mais racionais e sustentáveis, ao prover insights sobre eventuais diferenças nas culturas de investigação científica entre os PPG, em especial da área de Economia.

Portanto, visando facilitar a compreensão do impacto das atividades de pesquisa, com o uso de indicadores elaborados a partir dos dados disponibilizados pelo Sistema de Avaliação da Capes, o objetivo geral desta pesquisa foi elaborar e analisar um conjunto de indicadores científicos, com base na área de visualização de informação. Para alcançar este objetivo foi utilizado o método de pesquisa estudo de caso e a unidade caso compreendeu nove PPG da área de Economia avaliados pelo Sistema Capes em 2013, que corresponde ao triênio 2010, 2011 e 2012. A área de economia foi selecionada devido ao seu impacto sobre questões relacionadas ao desenvolvimento econômico e social do Brasil.

\subsection{Avaliação da ciência}

A avaliação da ciência tem como um de seus objetivos medir a eficiência de investimentos e a efetividade de seus resultados quanto aos impactos sociais, ambientais e econômicos (ZACKIEWICZ, 2003). De acordo com Liberal (2005) "os indicadores representam, descrevem e caracterizam um determinado fenômeno, além de identificar a sua natureza, estado e evolução". Na visão de (PRESSER; SILVA; SANTOS, 2010, p. 251) "a principal característica de um indicador é a sua capacidade de sintetizar um conjunto de informações, representando apenas o significado essencial dos aspectos analisados", e para Bellen $^{3}$ (2005 apud PRESSER; SILVA; SANTOS, 2010, p. 251) "os indicadores agregam e quantificam informações de modo que sua significância torne-se mais evidente".

No Brasil, assim como em outros países, são as universidades que têm um envolvimento direto com a pesquisa científica por meio dos PPG stricto-sensu. Assim, o Sistema de Avaliação da Capes é de significativa relevância para entender a dinâmica da ciência brasileira, com a necessária elaboração dos indicadores de desempenho dos PPG. A Capes ${ }^{4}$, vinculada ao

3 BELLEN, H.M.V. Indicadores de sustentabilidade: uma análise comparativa. Rio de Janeiro: Editora FGV, 2005.

${ }^{4}$ http://www.capes.gov.br/

\begin{tabular}{l|l|l|l|l|l}
\hline (C) RDBCI: Rev. Digit. Bibliotecon. Cienc. Inf. & Campinas, SP & v.15 & n.2 & p. 324-348 & maio/ago. 2017 \\
\hline
\end{tabular}


Ministério da Educação e Cultura (MEC) é a principal agência do Sistema Nacional de PósGraduação (SNPG), sendo reconhecida como órgão responsável pela elaboração do Plano Nacional de Pós-Graduação stricto-sensu, cuja responsabilidade, de acordo com Meijia Trujillo (2013, p. 09) é "elaborar, avaliar, acompanhar e coordenar as atividades relativas ao ensino superior", junto ao sistema nacional de ciência e tecnologia. E ainda, "é ela quem autoriza a abertura de novos PPG, e avalia os PPG em funcionamento periodicamente" (PACIEVITCH, 2016, p. 01).

O Sistema de Avaliação da Capes compreende diversos indicadores de natureza qualitativa e quantitativa (SOARES, 2002; HORTALE, 2003): quantidade de docentes, produção bibliográfica, teses e dissertações, projetos de pesquisa, entre outros. Para a realização das atividades avaliativas, são constituídos representantes, responsáveis por coordenar a avaliação em suas respectivas áreas de conhecimento e formar as comissões, responsáveis pela avaliação trienal dos PPG. Assim, de acordo com Baumgarten (2004, p. 43), a coletividade científica acadêmica está presente nas comissões de área, que "cumprem uma pauta de trabalho regular e sistemática junto à Capes". Os resultados desse processo de avaliação são expressos pela atribuição de uma nota na escala de "1" a "7", sendo que as notas 6 e 7 são exclusivas para programas com cursos de doutorado e que apresentam alto nível de excelência internacional; a nota 5 é a nota máxima para programas de mestrado; a nota 04 indica bom desempenho; a nota 3 representa o padrão mínimo de qualidade, sobre quais, os PPGs obtém aprovação e a renovação para continuar sua atuação, e consequentemente a validação do diploma até a próxima avaliação; e os programas que recebem as notas 1 e 2 deixam de ser reconhecidos pela Capes e suas autorizações para oferecimento dos cursos são canceladas.

O resultado da avaliação tem reflexos financeiros para os PPG, já que agências financiadoras de pesquisa, em âmbito federal ou estadual, tomam como principal indicador o resultado da avaliação do PPG, na definição sobre sua estratégia de financiamento (HORTA; MORAES, 2005, p. 101). Esse processo de avaliação dos PPG é realizado a cada 3 anos e recebe o nome de "Avaliação Trienal". Esta avaliação segue a regras e quesitos estabelecidos pelo Conselho Técnico Científico da Educação Superior (CTC-ES) ${ }^{5}$.

De acordo com Hortale (2003, p. 1839), observadores estrangeiros acompanharam o processo de avaliação dos PPG stricto-sensu de algumas áreas do conhecimento no ano de 2001, que é o modelo que vigora até os dias de hoje "e foram unânimes em considerar o modelo de avaliação adotado pela Capes coerente na sua generalidade e com uma qualidade avaliativa elevada". Todavia, ainda segundo Hortale (2003, p. 1839) “dos comentários feitos pelos

\footnotetext{
${ }^{5}$ O CTC-ES da CAPES é formado por dois representantes de cada uma das grandes áreas (Humanidades, Ciências da Vida, Ciências Exatas, Tecnológicas e Multidisciplinar) indicados pelos representantes de área, além do presidente e de três diretores da CAPES, de um Representante do Fórum Nacional de Pró-Reitores de Pesquisa e Graduação-FOPROP e de um Representante da Associação Nacional de Pós-Graduandos-ANPG.
}

\begin{tabular}{l|l|l|l|l|l}
\hline (C) RDBCI: Rev. Digit. Bibliotecon. Cienc. Inf. & Campinas, SP & v.15 & n.2 & p. 324-348 & maio/ago. 2017 \\
\hline
\end{tabular}


observadores, o que mais chamou a atenção foi que o Sistema de Avaliação da Capes está mais orientado para a pesquisa do que para a qualidade do ensino". Observou-se que "no instrumento de avaliação utilizado, não há indicadores próprios para avaliar os métodos de ensino, uma vez que, a qualidade dos cursos é inferida com base na análise do número de publicações, da qualificação do corpo docente, das orientações realizadas e da carga horária docente no Programa". Deixando de lado "competências pedagógicas e científicas que nem sempre emanam das atividades de pesquisa", como conclui Spagnolo e Calhau ${ }^{6}$ (2002 apud HORTALE, 2003, p. 1839).

Os autores Horta e Moraes (2005, p. 101) complementam sobre o impacto que pode causar esse tipo de avaliação ao dizer que o modelo torna-se um círculo vicioso onde "docentes de programas com notas mais altas dedicam mais tempo à produção científica, garantindo assim a manutenção destas, e o financiamento por parte dos órgãos que consideram fundamental a nota no momento da distribuição das verbas", em detrimento da qualidade do ensino. Já docentes de programas com notas mais baixas "buscam desesperadamente que todos os seus orientandos titulem o mais rapidamente possível, para que seus programas não percam as bolsas da Capes" (HORTA; MORAES, 2005, p. 101).

Apesar das críticas, a Capes vem buscando aperfeiçoar seu sistema de avaliação, e em 2014 lançou uma nova e importante ferramenta para coletar informações, realizar análises e avaliações, com o intuito de ser à base de referência para o SNPG. Trata-se da plataforma Sucupira (MEC, 2014), cuja escolha do nome é uma homenagem a Newton Lins Buarque Sucupira, que instituiu a pós-graduação brasileira nos moldes como é até os dias de hoje (BOMENY, 2014).

Com a implantação dessa plataforma, o sistema informatizado conhecido como "Coleta-Capes" foi reformulado e passou a ser um dos módulos da nova plataforma. As informações coletadas sobre os PPG, após analisadas são divulgadas para a sociedade, pelos Cadernos de Indicadores e pela Planilha de Indicadores da Capes. Além de prover à Capes "informações necessárias ao planejamento dos seus programas de fomento e delineamento de suas políticas institucionais", também contribui "para a constituição da chamada memória da Pós-Graduação, que é o acervo de informações consolidadas sobre o SNPG” (MEC, 2014, p. 06). A plataforma tem como objetivo otimizar a coleta de dados, e ainda, dar imediata visibilidade e maior transparência das informações sobre o desempenho dos PPG para a sociedade, o que contribui para a "redução de tempo e esforços na execução da avaliação do SNPG", bem como "maior confiabilidade, precisão e segurança das informações", dentre outros benefícios (MEC, 2014, p. 07).

\footnotetext{
${ }^{6}$ Spagnolo, F.; Calhau, M. G. Observadores internacionais avaliam a avaliação da CAPES. Infocapes - Boletim Informativo da CAPES. Brasília, v. 10, n. 1, p. 7-34, 2002.
}

\begin{tabular}{l|l|l|l|l|l}
\hline (C) RDBCI: Rev. Digit. Bibliotecon. Cienc. Inf. & Campinas, SP & v.15 & n.2 & p. 324-348 & maio/ago. 2017 \\
\hline
\end{tabular}




\subsection{Visualização de Informação}

$\mathrm{Na}$ apresentação dos indicadores é possível fazer uso de diferentes tipologias de gráficos na tentativa de revelar informações úteis ao processo de cognição para analistas e tomadores de decisão. A área de pesquisa visualização de informação (Information Visualization) estuda a maneira como as representações visuais podem ser implementadas com o auxílio da tecnologia da informação e comunicação (computadores e softwares), procurando auxiliar e facilitar o processo de cognição (SILVA, 2006). Nesse sentido as pesquisas em visualização de informação indicam que, para dar sentido aos dados, visando a tomada de decisões mais racionais e sustentáveis, se faz necessário conhecer e aplicar as regras da visão.

Com base nos estudos de Few (2009) é possível afirmar que, 90\% das análises de dados realizadas pela maioria das organizações, poderiam ser elaboradas usando um simples conjunto de competências, pois requerem apenas uma compreensão básica de um conjunto de regras da visão para explorar os dados e descobrir padrões significativos. A visualização de informação contribui para o sucesso da comunicação, quando as suas ferramentas e processos estão alinhados com os pontos fortes da percepção visual humana e da cognição nos permitindo identificar relações, padrões, tendências e exceções, ou seja, a visualização de informação também deve estar embasada em uma compreensão de como as pessoas pensam; só então, visualizações poderão apoiar as operações cognitivas que darão sentido à informação, portanto, ao desejar exibir informações de uma forma que permita fazer sentido, é preciso entender e seguir as regras da visão relacionadas abaixo para que se obtenha sucesso no processo de comunicação (FEW, 2009):

a) Forma: comprimento, largura, tamanho. Estas formas são muito usadas para representar e comparar facilmente valores. O mais comum são os gráficos de barras/colunas, que usam as colunas (comprimento vertical) ou as barras (comprimento horizontal) para representar valores. Outro exemplo, são gráficos de caixas que são usados para exibir a distribuição de todo um conjunto de valores do menor para o maior, juntamente com pontos significativos no meio, tais como a mediana (valor médio). Nos gráficos de rede a largura das linhas representa a quantidade das conexões. Já os "mapas de árvores" ou "treemaps", podem mostrar duas variáveis quantitativas simultaneamente: uma representada pelo tamanho de cada elemento e outra representada pela cor (intensidade), no entanto, mapas de árvores não foram projetados para suportar comparações quantitativas precisas como os gráficos de barras, mas, é um tipo de visualização que pode exibir o máximo de itens hierarquicamente estruturados de uma só vez. Ou seja, a forma é utilizada para organizar dados, do maior para o menor, assim como para representar valores quantitativos (FEW, 2009);

b) Cor: colorido/tonalidade, intensidade (fraco/forte). De acordo com Few (2009), a cor está entre as regras da visão mais fáceis de se perceber. Percebe-se a cor não em termos absolutos, mas a diferença entre a cor focada e a cor ao redor. Em muitos gráficos, tais como os de dispersão, os de barra e os de linha pode-se usar, por exemplo, tons (tonalidade da cor 
$=$ maior/menor, intensidade da cor $=$ maior/menor) para associar objetos (barras ou linhas) e categorias específicas. Um outro exemplo, é o uso do "mapa de calor", que codifica valores em um mapa geográfico, em que as cores são usadas para representar variações de temperatura ou de precipitação;

c) Posição espacial: posição 2-D/localização, agrupamento espacial. A posição é percebida quantitativamente com alto grau de precisão por representar com muita clareza a informação: maior/menor que está relacionada ao agrupamento espacial de dados (posição horizontal ao longo do eixo-X e posição vertical ao longo do eixo-Y). A localização nos permite ver padrões, tendências e exceções, pois facilita a comparação de um valor com outro simplesmente porque os valores estão próximos. Ainda de acordo com Few (2009), os dados também podem ser representados através de posições 2-D por meio de objetos simples (pontos, praças, triângulos, e assim por diante) para codificar os valores. Por fim, linhas que usam as posições 2-D de pontos conectados também podem ser utilizadas para dar forma a uma série de valores;

d) Movimento: direção. Ao observar a direção dos dados em uma imagem, é possível acompanhar suas mudanças e alterações. Por exemplo, no caso de valores quantitativos que foram alterados durante um período contínuo de tempo, o gráfico de linha torna visível o fluxo sequencial desses valores e como eles mudam com a passagem do tempo. Por sua própria natureza, uma linha traça claramente a conexão de um valor para o próximo e através de sua inclinação exibe a extensão e a direção da mudança. Já o gráfico de dispersão, por exemplo, permite observar valores durante um período de tempo que tendem a mover em uma direção similar ou em uma direção diferente, movendo-se para cima, da esquerda para a direita (correlação positiva), para baixo, da esquerda para a direita (correlação negativa) (FEW, 2009). Há outros tipos de gráficos, como por exemplo, o Gapminder, que viabilizam utilizar a regra do movimento, pois trata-se de um gráfico dinâmico.

Segundo Volpato (2011, p. 148) a comunidade científica precisa se apropriar dos conceitos da área de visualização de informação, "infelizmente, somos amadores na comunicação visual, mas, o uso do bom senso já ajuda muito". O jornalismo científico tem usufruído da visualização de informação para a elaboração e apresentação dos resultados das pesquisas científicas, que tem contribuído para a difusão da ciência e do conhecimento científico, buscando criar uma relação mais próxima com o cidadão comum. Alves (2010), Modolo (2007) e Schmitt (2006) relatam experiências sobre o uso da visualização de informação no jornalismo científico. Inclusive, é importante comentar que em muitos trabalhos é possível encontrar o termo "infografia" como sinônimo para visualização de informação.

A visualização de informação ainda é pouco explorada para auxiliar a análise e compreensão de indicadores relacionados ao desempenho das atividades científicas, mas existem algumas iniciativas que merecem ser destacadas: 
a) National Science Foundation (NSF): disponibiliza um conjunto de indicadores interativos sobre a ciência americana (NATIONAL, 2014).

b) SCImago: Compreende iniciativas que contribuem para a visualização de indicadores científicos, para a geração de rankings que permitem analisar e avaliar a produção de pesquisa das universidades e instituições e a análise dos principais indicadores científicos contidos na base de dados Scopus referente a cada país. É "um sistema de informação cujo objetivo é conseguir uma representação gráfica da Pesquisa Científica Ibero-americana. Esta representação é concebida como uma coleção de mapas interativos que permitem a navegação através dos espaços semânticos formados pelos mapas" (SCIMAGO, 2011, p. 01);

c) GeoCapes: Essa ferramenta apresenta "mapas interativos que exibem, em escala de cores, a variação numérica de indicadores selecionados, para cada município, unidade da Federação ou país. Além disso, a ferramenta oferece opções de visualização de gráficos e de tabelas com dados referentes a vários indicadores. A Capes também disponibiliza os relatórios e planilhas relacionadas a Avaliação Trienal 2013, que "podem ser visualizados em formato de gráfico, com possibilidades de filtros por área, região, nota e IES" (CAPES, 2015, p. 01);

d) Vlab4u: grupo de pesquisa em informação que compreende o tratamento e análise de grandes volumes de dados de acesso livre na web (VLAB4U, 2016).

e) Painel Lattes: iniciativa do $\mathrm{CNPq}$ para representar a atuação e distribuição dos pesquisadores em Ciência, Tecnologia e Inovação, utilizando dados estatísticos da Plataforma Lattes. A visualização disponibilizada retrata diversos indicadores macros da ciência brasileira (PAINEL, 2016).

O uso da visualização de informação auxilia na compreensão de grandes quantidades de informação, pois simplifica e facilita a compreensão dos dados por meio do uso de representações visuais dos resultados das pesquisas, contribuindo, assim, para a divulgação científica, transpondo a barreira existente entre a comunidade acadêmica e a sociedade.

\section{MÉTODO/ DESENVOLVIMENTO DA PESQUISA}

Como método de pesquisa foi utilizado o estudo de caso e a unidade caso foram os nove PPG da área de Economia avaliados pelo Sistema de Avaliação da Capes no triênio de 2013. Além do fato da área de economia impactar sobre questões relacionadas ao desenvolvimento econômico e social do Brasil, a área foi escolhida por haver grande interesse na compreensão dos resultados da avaliação trienal da Capes, pois, apresenta um case muito interessante para esta pesquisa. O Instituto de Economia da Unicamp possui dois programas de mestrado e dois programas de doutorado que apresentam a peculiaridade de notas distintas tendo participado

\begin{tabular}{l|l|l|l|l|l}
\hline (C) RDBCI: Rev. Digit. Bibliotecon. Cienc. Inf. & Campinas, SP & v.15 & n.2 & p. 324-348 & maio/ago. 2017 \\
\hline
\end{tabular}


de um mesmo processo de avaliação, por isso, o programa de Desenvolvimento Econômico da Unicamp, que recebeu nota quatro, também fez parte da seleção da amostra, uma vez que haviam sido selecionados primeiramente, somente os programas com notas 7 e 6 . Assim, a elaboração de indicadores com base nos conceitos de visualização pode facilitar a compreensão das diferenças no desempenho dos PPG.

Os 09 programas selecionados dentre os 42 PPG na área de Economia no Brasil foram: os três programas que receberam nota sete no Triênio de 2013, Economia (USP), Economia (FGV/RJ), Economia de empresas (FGV/SP), os cinco programas que receberam nota 06, Economia (UFMG), Desenvolvimento Econômico (UFPR), Economia (UNB), Economia (Puc-Rio), Ciência Econômica (Unicamp -CE), e o programa com nota 4 do mesmo instituto (UNICAMP-DE - Desenvolvimento Econômico), totalizando nove programas sintetizados na FIGURA 1, com suas respectivas notas.

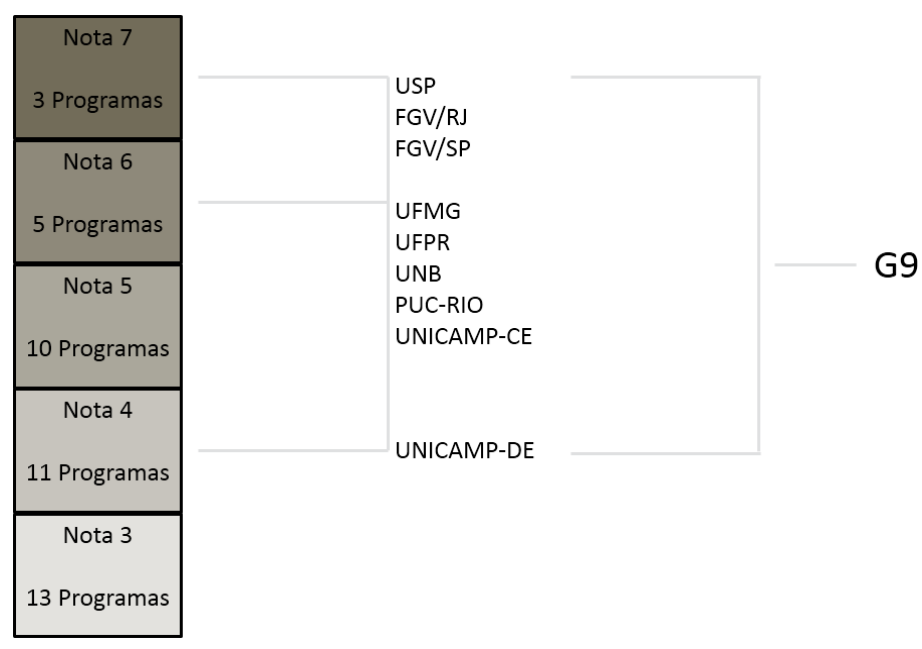

Figura 1 - Amostra da pesquisa - PPG em Economia - G9

Fonte: Elaborado pelos autores a partir dos dados extraídos da Planilha de Indicadores (CAPES, 2014).

Foram utilizados como fonte de informação o Documento de Área da Avaliação Trienal 2013, o Relatório da Avaliação Trienal 2013, as Fichas de Avaliação, os Cadernos de Indicadores da Capes e a Planilha de Indicadores referentes ao triênio de 2013. Na visão de Marconi e Lakatos (2010), os documentos constituem em uma fonte poderosa de informação, pois fornecem dados de um determinado contexto, além do mais, os documentos podem explicar um determinado objeto e os fenômenos relacionados a problemática da pesquisa.

Os procedimentos metodológicos empregados nesta pesquisa envolveram as etapas sintetizadas na FIGURA 2 e no QUADRO 1.

\begin{tabular}{l|l|l|l|l|l}
\hline (C) RDBCI: Rev. Digit. Bibliotecon. Cienc. Inf. & Campinas, SP & v.15 & n.2 & p. 324-348 & maio/ago. 2017 \\
\hline
\end{tabular}




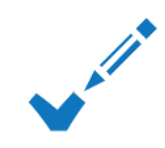

Seleção da Amostra

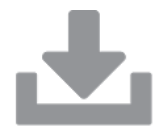

Coleta dos dados

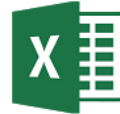

Preparação dos dados

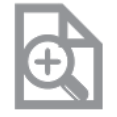

Análise exploratória
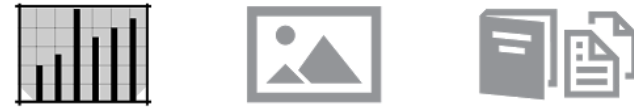

Definição dos indicadores

Figura 2 - Síntese dos procedimentos metodológicos - visualização gráfica Fonte: Elaborado pelos autores

Quadro 1- Procedimentos metodológicos

\begin{tabular}{|c|c|}
\hline $\begin{array}{l}\text { Procedimento } \\
\text { Metodológico }\end{array}$ & Descrição \\
\hline Seleção da Amostra & $\begin{array}{l}\text { Foram selecionados dentre os } 42 \text { PPG em Economia do Brasil, os três programas } \\
\text { que receberam nota sete no Triênio de } 2013 \text {, (USP, FGV/SP e FGV/RJ), os cinco } \\
\text { programas que receberam nota } 06 \text { (UFMG, UFPR, UNB, PUC-RIO, UNICAMP-CE } \\
- \text { Ciência Econômica), e um programa com nota } 4 \text { (UNICAMP-DE- } \\
\text { Desenvolvimento Econômico), totalizando nove programas, para compor a amostra } \\
\text { analisada nesta pesquisa. Com o intuito de maximizar a compreensão da comparação } \\
\text { da evolução de cada programa com relação a algumas das dimensões do Sistema de } \\
\text { Avaliação da Capes, optou-se por nomear este grupo de G9 (grupo dos 9). }\end{array}$ \\
\hline Coleta dos dados & $\begin{array}{l}\text { Os dados foram obtidos por intermédio da análise documental de } 03 \text { dos } 12 \text { Cadernos } \\
\text { de Indicadores da Capes: TE - Teses e Dissertações, PB - Produção Bibliográfica, } \\
\text { CD - Corpo Docente, Vinculo e formação correspondentes aos programas de } \\
\text { mestrado acadêmico e doutorado na área de Economia, e da Planilha de Indicadores } \\
\text { disponíveis no site da Capes do Triênio de } 2013 \text {. }\end{array}$ \\
\hline Preparação dos dados & $\begin{array}{l}\text { Em seguida foi realizada a compilação dos dados, em planilhas do Microsoft Excel } \\
\text { e Gapminder. }\end{array}$ \\
\hline Análise exploratória & $\begin{array}{l}\text { Análise exploratória para o desenvolvimento dos gráficos para apresentação dos } \\
\text { indicadores, uma vez que os dados apresentados pela Capes não são } \\
\text { disponibilizados com formato e estrutura visual adequados a realização de } \\
\text { comparações de desempenho entre os PPG da área de Economia, o que dificulta a } \\
\text { compreensão do desempenho dos PPG. }\end{array}$ \\
\hline $\begin{array}{l}\text { Definição dos } \\
\text { indicadores }\end{array}$ & $\begin{array}{l}\text { Definição de um conjunto de indicadores que possibilitassem a realização da análise } \\
\text { e da comparação de desempenho entre os PPG com base nas dimensões do Sistema } \\
\text { de Avaliação da Capes. }\end{array}$ \\
\hline $\begin{array}{l}\text { Elaboração e } \\
\text { visualização dos } \\
\text { Indicadores }\end{array}$ & $\begin{array}{l}\text { Seleção, elaboração e apresentação dos indicadores com base nos conceitos da área } \\
\text { de visualização de informação. }\end{array}$ \\
\hline
\end{tabular}

Fonte: Elaborado pelos autores

Embora a Capes apresente a facilidade no acesso às informações, os Cadernos de Indicadores estão disponibilizados em arquivos no formato PDF, o que dificulta a extração e compilação dos dados, pois precisam ser exportados para uma planilha do Microsoft Excel para a edição dos dados. Ao passo que a Planilha de Indicadores já está disponibilizada em formato do Microsoft Excel e facilita a extração e compilação dos dados contidos nela. Por fim, ao utilizar recursos gráficos, é possível interagir com os dados coletados, o que viabiliza extrair rapidamente mais informação do que os dados apresentados em tabelas, planilhas, etc., na forma textual (SILVA, 2006).

\begin{tabular}{l|l|l|l|l|l}
\hline (C) RDBCI: Rev. Digit. Bibliotecon. Cienc. Inf. & Campinas, SP & v.15 & n.2 & p. 324-348 & maio/ago. 2017 \\
\hline
\end{tabular}




\section{RESULTADOS}

A sistemática utilizada para a definição e elaboração dos indicadores com base na área de visualização de informação para representar e comparar o desempenho dos PPG está sintetizada nos Quadros 2, 3 e 4 - Dimensões da Avaliação Trienal 2013, compreendidas pelo Sistema de Avaliação da Capes, que viabiliza comparações entre o desempenho dos PPG da área de Economia.

Neles estão descritos alguns dos indicadores selecionados, a análise de como estes indicadores estão disponibilizados pela Capes, e ainda, o que não é possível visualizar da forma como estão disponibilizados. Após análise do que não é possível visualizar, foram elaborados alguns gráficos com base na área de visualização de informação, e por fim apresenta-se os benefícios alcançados.

Quadro 2 - Dimensões da avaliação da Capes no triênio de 2013 - Corpo docente - Indicador Endogenia .

\begin{tabular}{|c|c|c|c|c|}
\hline $\begin{array}{l}\text { Como estão } \\
\text { disponibilizados } \\
\text { pela Capes }\end{array}$ & $\begin{array}{c}\text { O que não é } \\
\text { possível } \\
\text { visualizar }\end{array}$ & $\begin{array}{l}\text { Apresentação } \\
\text { visual } \\
\text { indicada }\end{array}$ & $\begin{array}{c}\text { Regras de } \\
\text { visualização } \\
\text { de } \\
\text { informação }\end{array}$ & $\begin{array}{c}\text { Benefícios ao se utilizar as } \\
\text { regras de visualização de } \\
\text { informação }\end{array}$ \\
\hline $\begin{array}{l}\text { Este indicador está } \\
\text { presente no } \\
\text { Caderno de } \\
\text { indicadores 2010- } \\
2012 \text { "CD - Corpo } \\
\text { Docente, Vinculo e } \\
\text { formação", em } \\
\text { formato PDF, e os } \\
\text { dados totais de } \\
\text { docentes estão na } \\
\text { Planilha de } \\
\text { Indicadores em } \\
\text { formato do } \\
\text { Microsoft Excel. }\end{array}$ & $\begin{array}{c}\text { Estes } \\
\text { documentos não } \\
\text { permitem } \\
\text { realizar } \\
\text { comparações, } \\
\text { pois os dados } \\
\text { além de estarem } \\
\text { separados em } \\
\text { vários arquivos } \\
\text { (um para cada } \\
\text { ano) a própria } \\
\text { extensão do } \\
\text { documento } \\
\text { (PDF) não } \\
\text { facilita gerar } \\
\text { gráficos. }\end{array}$ & $\begin{array}{c}\text { Gráfico - } \\
\text { Gapminder. } \\
\text { Dentre os } \\
\text { gráficos } \\
\text { utilizados nesta } \\
\text { pesquisa, o } \\
\text { Gapminder é o } \\
\text { único que } \\
\text { permite explorar } \\
\text { o movimento, } \\
\text { que possibilita } \\
\text { visualizar a } \\
\text { evolução de } \\
\text { dados por um } \\
\text { determinado } \\
\text { período. } \\
\text { Além disso, } \\
\text { diferente dos } \\
\text { demais ele } \\
\text { possibilita a } \\
\text { interação com } \\
\text { os dados de } \\
\text { forma rápida, } \\
\text { através de um } \\
\text { clique de mouse } \\
\text { possibilitando } \\
\text { diversas } \\
\text { análises. }\end{array}$ & $\begin{array}{l}\text { Cor, tamanho, } \\
\text { posição e } \\
\text { movimento. }\end{array}$ & $\begin{array}{l}\text { O Gapminder possibilita utilizar } \\
\text { quatro regras da área de } \\
\text { visualização de informação: a } \\
\text { cor para categorizar; o tamanho } \\
\text { dos círculos para representar } \\
\text { quantidade; a posição e o } \\
\text { movimento para visualizar a } \\
\text { evolução dos dados, o que } \\
\text { possibilita alcançar uma boa } \\
\text { comunicação. Além disso, há } \\
\text { várias maneiras de interagir com } \\
\text { os dados que são especialmente } \\
\text { úteis para a sua compreensão, e } \\
\text { dentre estas está a revisualização } \\
\text { com a troca de dados de forma } \\
\text { rápida - com um clique do } \\
\text { mouse - possibilitando diversas } \\
\text { análises. Assim, quando a } \\
\text { informação é apresentada } \\
\text { visualmente, é dado forma, o que } \\
\text { permite obter facilmente insights } \\
\text { que seriam difíceis ou } \\
\text { impossíveis de perceber a partir } \\
\text { dos mesmos dados apresentados } \\
\text { textualmente e de forma estática } \\
\text { (FEW,2009). }\end{array}$ \\
\hline
\end{tabular}

Fonte: Elaborado pelos autores

\begin{tabular}{l|l|l|l|l|l}
\hline (C) RDBCI: Rev. Digit. Bibliotecon. Cienc. Inf. & Campinas, SP & v.15 & n.2 & p. 324-348 & maio/ago. 2017 \\
\hline
\end{tabular}


Quadro 3 - Dimensões da avaliação da Capes no triênio de 2013 - Corpo discente, Teses e Dissertações - Indicador quantidade de teses e dissertações defendidas.

\begin{tabular}{|c|c|c|c|c|}
\hline $\begin{array}{c}\text { Como estão } \\
\text { disponibilizados } \\
\text { pela Capes }\end{array}$ & $\begin{array}{l}\text { O que não } \\
\text { é possível } \\
\text { visualizar }\end{array}$ & $\begin{array}{l}\text { Apresentaçã } \\
\text { o visual } \\
\text { indicada }\end{array}$ & $\begin{array}{c}\text { Regras de } \\
\text { visualização } \\
\text { de } \\
\text { informação } \\
\end{array}$ & $\begin{array}{c}\text { Benefícios ao se utilizar as } \\
\text { regras de visualização de } \\
\text { informação }\end{array}$ \\
\hline $\begin{array}{l}\text { Este indicador está } \\
\text { disponível na } \\
\text { Planilha de } \\
\text { Indicadores da } \\
\text { Avaliação Trienal } \\
2013 \text { no formato do } \\
\text { Microsoft Excel. }\end{array}$ & $\begin{array}{c}\text { As } \\
\text { informações } \\
\text { sobre a } \\
\text { quantidade } \\
\text { de teses e } \\
\text { dissertações } \\
\text { defendidas } \\
\text { estão } \\
\text { disponibiliz } \\
\text { adas em } \\
\text { tabelas que } \\
\text { permitem a } \\
\text { leitura de } \\
\text { valores } \\
\text { individuais } \\
\text { (um por } \\
\text { vez), pois, é } \\
\text { a forma } \\
\text { como } \\
\text { percebemos } \\
\text { as tabelas, } \\
\text { portanto, } \\
\text { não é } \\
\text { possível } \\
\text { obter uma } \\
\text { visão ampla } \\
\text { de todas as } \\
\text { informações } \\
\text { contidas } \\
\text { nelas. }\end{array}$ & $\begin{array}{c}\text { Gráfico - } \\
\text { Gapminder. } \\
\text { Que permite } \\
\text { explorar o } \\
\text { movimento, e } \\
\text { possibilita } \\
\text { visualizar a } \\
\text { evolução de } \\
\text { dados por um } \\
\text { determinado } \\
\text { período. } \\
\text { Também } \\
\text { possibilita a } \\
\text { revisualização } \\
\text { e ou troca de } \\
\text { dados de } \\
\text { forma rápida. }\end{array}$ & $\begin{array}{l}\text { Cor, tamanho, } \\
\text { posição e } \\
\text { movimento. }\end{array}$ & $\begin{array}{l}\text { O uso do Gapminder permite uma } \\
\text { visão ampla de todas as informações. } \\
\text { Novamente foi possível utilizar quatro } \\
\text { regras da área de visualização de } \\
\text { informação: a cor para categorizar os } \\
\text { programas; o tamanho dos círculos } \\
\text { para representar a quantidade/média; } \\
\text { a posição e o movimento que } \\
\text { permitem visualizar a evolução de } \\
\text { todos os dados durante o Triênio de } \\
\text { 2013. Além do mais, quando os } \\
\text { valores quantitativos são apresentados } \\
\text { como imagens visuais que apresentam } \\
\text { padrões significativos, a informação é } \\
\text { fragmentada em conjunto nestas } \\
\text { imagens, de modo que é possível } \\
\text { analisar um maior volume de } \\
\text { informações ao mesmo tempo do que } \\
\text { se estivesse utilizando tabelas ou } \\
\text { texto por si só, pois, os gráficos } \\
\text { multiplicam o número e a } \\
\text { complexidade dos insights que podem } \\
\text { surgir Few (2009). Com este gráfico } \\
\text { em específico (o Gapminder) é } \\
\text { possível obter interação entre os } \\
\text { dados de várias maneiras, como por } \\
\text { exemplo: adicionar variável, etc. }\end{array}$ \\
\hline
\end{tabular}

Fonte: Elaborado pelos autores 
Quadro 4 - Dimensões da avaliação da Capes no triênio de 2013 - Produção Intelectual Indicador produtividade da área, ponderada pela quantidade dos veículos.

\begin{tabular}{|c|c|c|c|c|}
\hline $\begin{array}{l}\text { Como estão } \\
\text { disponibilizados } \\
\text { pela Capes }\end{array}$ & $\begin{array}{l}\text { O que não } \\
\text { é possível } \\
\text { visualizar }\end{array}$ & $\begin{array}{l}\text { Apresentação } \\
\text { visual } \\
\text { indicada }\end{array}$ & $\begin{array}{l}\text { Regras de } \\
\text { visualização } \\
\text { de } \\
\text { informação }\end{array}$ & $\begin{array}{l}\text { Benefícios ao se utilizar as } \\
\text { regras de visualização de } \\
\text { informação }\end{array}$ \\
\hline $\begin{array}{l}\text { Este indicador está } \\
\text { disponível na } \\
\text { Planilha de } \\
\text { Indicadores da } \\
\text { Avaliação Trienal } \\
2013 \text { no formato do } \\
\text { Microsoft Excel. }\end{array}$ & $\begin{array}{l}\text { As planilhas } \\
\text { são boas } \\
\text { para analisar } \\
\text { dados } \\
\text { individuais, } \\
\text { mas, não } \\
\text { permitem } \\
\text { realizar } \\
\text { comparaçõe } \\
\text { s, identificar } \\
\text { padrões de } \\
\text { comportame } \\
\text { nto, etc. }\end{array}$ & $\begin{array}{c}\text { Gráfico de } \\
\text { Colunas. Para } \\
\text { Yau (2012), o } \\
\text { gráfico de } \\
\text { colunas é um } \\
\text { dos tipos mais } \\
\text { comuns e pode } \\
\text { ser usado para } \\
\text { vários tipos de } \\
\text { dados. }\end{array}$ & $\begin{array}{l}\text { Grafico de } \\
\text { Colunas: } \\
\text { comprimento } \\
\text { e cor. }\end{array}$ & $\begin{array}{c}\text { Segundo Few (2009), nossos olhos } \\
\text { são naturalmente atraídos para as } \\
\text { tendências, padrões e exceções que } \\
\text { seria difícil ou impossível encontrar } \\
\text { em tabelas e planilhas. Visualização } \\
\text { de informação é ideal para a análise } \\
\text { exploratória de dados. Neste caso } \\
\text { foi utilizado o gráfico de colunas, e } \\
\text { como regra da visão o comprimento } \\
\text { das colunas, pois é possível } \\
\text { compará-las facilmente, e a cor para } \\
\text { categorizar os programas, e ao } \\
\text { mesmo tempo também proporciona } \\
\text { uma análise individual e uma visão } \\
\text { geral de cada coisa. Para Few (2009) } \\
\text { ter uma visão geral é muito } \\
\text { importante. Ela reduz o tempo de } \\
\text { busca, permite a detecção de } \\
\text { padrões globais, e auxilia o usuário } \\
\text { a escolher o próximo movimento. } \\
\text { Ou seja, geralmente a heurística da } \\
\text { visualização começa com uma visão } \\
\text { geral, que permite ao usuário } \\
\text { acessar informações rapidamente. }\end{array}$ \\
\hline
\end{tabular}

Fonte: Elaborado pelos autores

O uso dos conceitos da visualização de informação facilita a compreensão das dinâmicas da ciência e provê insights significativos para os tomadores de decisão, que atuam especialmente na implementação de políticas públicas e na gestão dos PPG.

As dimensões da Avaliação Trienal 2013 que avalia os PPG são feitas com base em cinco quesitos, padronizados para todas as áreas do conhecimento, a saber: proposta do programa; corpo docente; corpo discente, teses e dissertações; produção intelectual; inserção social e relevância, sendo que a comissão de cada área define o peso que cada quesito terá, divulgados no Documento de Área. Para a área de Economia, os quesitos "Corpo Discente, Teses e Dissertações" e "Produção Intelectual" são considerados mais relevantes na avaliação e representam os resultados dos programas em termos de novos pesquisadores formados e titulados e da produção científica dos mesmos associados à produção docente. Já o quesito Corpo docente é considerado ponto chave, pois, todas as análises são feitas com base na quantidade de docentes permanentes que cada programa possui. 


\subsection{Corpo docente}

No Relatório da Avaliação da Trienal 2013, no quesito Corpo Docente foram avaliados alguns indicadores: a titulação, a atuação do docente dentro do programa, se há intercâmbio de pesquisa, se ocorre endogenia etc. De modo geral, para a Capes a qualidade do corpo docente corresponde a um quadro de origem diversificada, portanto, a endogenia é um indicador negativo, e pode prejudicar o programa a alcançar a nota máxima dentro deste quesito. Este indicador é calculado pelo número de docentes permanentes (DP) titulados na mesma instituição dividido pelo total de docentes permanentes.

Os dados referentes à formação dos docentes dos programas estão presentes no Caderno de indicadores 2010-2012 "CD - Corpo Docente, Vínculo e formação" Capes (2010), e a primeira dificuldade encontrada para analisar esses dados é que além de estarem em formato PDF, os Cadernos estão divididos ano a ano. Portanto, foi necessário extrair os dados dos três documentos referentes aos anos de 2010, 2011 e 2012 e compilar os dados em uma planilha no Microsoft Excel do Googledocs para gerar o indicador corpo docente externalizado por intermédio do gráfico conhecido como Gapminder. Além disso, foram encontradas inconsistências nos dados disponibilizados pela Capes, com relação à quantidade de docentes permanentes. Uma hipótese para essa inconsistência pode estar relacionada a dinâmica de entrada e saída dos docentes, que pode influenciar diretamente na quantidade de docentes considerados permanentes durante a avaliação do PPG; então foi realizada uma simulação com os dados presentes nos Cadernos, porém não foi possível encontrar alterações significativas no comportamento de entrada e saída de docentes permanentes. Por fim, para chegar a um denominador comum com relação a quantidade de docentes permanentes a Comissão de área define a quantidade que será usada no momento da avaliação, baseada nos dados dos três anos correspondentes ao triênio e são disponibilizados na Planilha de Indicadores.

Sendo assim, optou-se por utilizar o gráfico Gapminder neste momento, somente para explorar a discrepância entre a endogenia apresentada pelos PPG, aqui analisados. Ao elaborar o Gráfico 1, foi possível utilizar quatro regras da área da visão: a cor para categorizar; o tamanho dos círculos para quantificar; a posição e o movimento que permitem visualizar a evolução dos dados durante o Triênio 2013 de forma dinâmica possibilitando uma boa comunicação. No entanto, não foi possível explorar a regra do movimento neste momento. Na visão de Few (2009) a eficácia da visualização de informação depende de duas coisas: da capacidade de representar de forma clara e com precisão as informações e a capacidade de interagir com ela para compreendê-la. O Gapminder possibilita interação com os dados de forma rápida com um clique do mouse possibilitando diversas análises. 


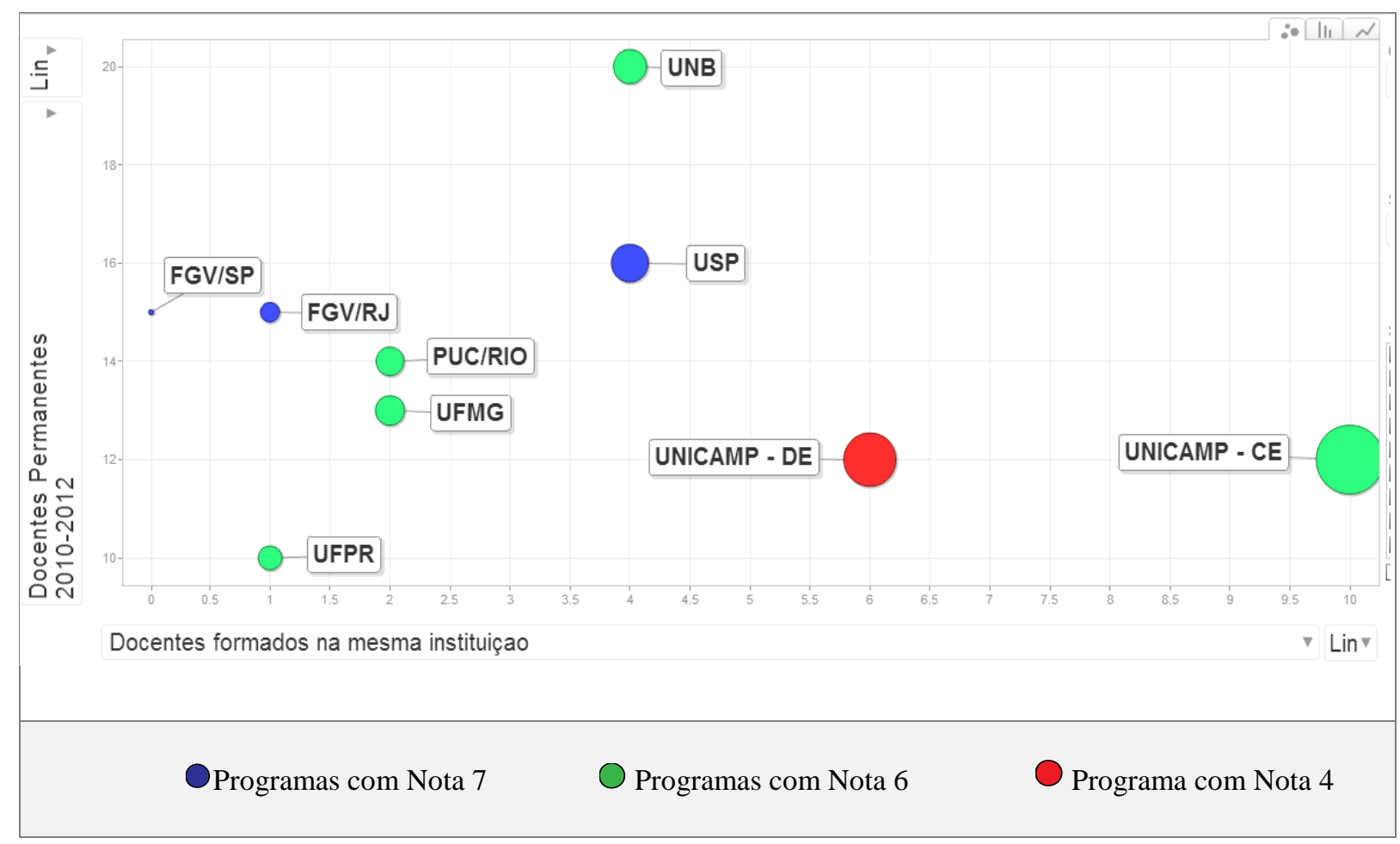

Gráfico 1 - Perfil corpo docente - G9 - Endogenia

Nota: O tamanho do círculo representa a quantidade de Docentes Permanentes ${ }^{7}$ titulados na mesma Instituição dividido pelo total de Docentes Permanentes $=$ Endogenia

Fonte: Elaborado pelos autores a partir das informações disponíveis nos Cadernos de Indicadores de 2012 "CD - Corpo Docente, Vínculo Formação" (CAPES, 2010) e na Planilha de Indicadores (CAPES, 2014).

É possível identificar no Gráfico 1, tanto pela posição quanto pelo tamanho dos pontos, que os dois PPG da Unicamp se destacam com relação a quantidade de docentes permanentes formados na mesma instituição. Ou seja, seu grau de endogenia é alto. Esta constatação corrobora com Schwartzman (2013) ao observar que a maioria dos doutores diplomados acabam trabalhando muito frequentemente nas mesmas universidades a partir do qual se formou. Ao analisar os programas com nota sete, há um padrão de comportamento com relação a quantidade de docentes permanente apresentando pouco ou nenhuma endogenia. No caso dos programas com nota 06 não há nenhum padrão de comportamento com relação a quantidade de docentes permanentes e endogenia.

De fato, possuir um quadro docente de natureza mais diversificada contribui para a qualidade dos PPG, pois há possibilidade de serem incorporadas experiências oriundas de outras instituições. Portanto, há necessidade de se entender melhor a endogenia na área de Economia, levando em consideração os estudos de Horta (2012) ao categorizar a carreira

\footnotetext{
${ }^{7}$ Enquadrados, declarados e relatados anualmente pelo programa, e que atendam a todos os requisitos da Portaria Capes n. 02 de 04 de Janeiro de 2012.
}

\begin{tabular}{l|l|l|l|l|l}
\hline (C) RDBCI: Rev. Digit. Bibliotecon. Cienc. Inf. & Campinas, SP & v.15 & n.2 & p. 324-348 & maio/ago. 2017 \\
\hline
\end{tabular}


acadêmica em vários perfis endógenos, pois, como aponta Braga e Venturini (2013), a carreira acadêmica tem sofrido diversas mudanças ao longo dos anos e merece ser reexaminada. A fim de entender a discrepância entre os PPG, uma forma possível é analisar como se dá a formação do corpo docente da área, e isso pode ser realizado através da investigação do número de teses e dissertações de cada um dos PPG analisados.

\subsection{Corpo discente, teses e dissertações}

Neste quesito são avaliados diversos indicadores como, por exemplo, a quantidade de teses e dissertações defendidas pelos discentes do programa, o número médio de orientações concluídas por docente permanente, a produção científica discente, etc. Estes dados encontramse na Planilha de Indicadores em formato do Microsoft Excel, que só permitem a leitura de valores individuais (um por vez) o que impossibilita fazer análises quando se tem um grande volume de dados.

Verificar a quantidade de teses e dissertações concluídas pelos PPG pode ajudar a entender a discrepância entre os PPG com relação a endogenia, uma vez que está diretamente ligada com o local de formação dos docentes. Portanto, para tentar compreender o comportamento dos programas com relação ao número de teses e dissertações defendidas e a média das orientações por docente permanente de cada um dos PPG analisados, optou-se novamente pelo gráfico Gapminder, que possibilita utilizar quatro regras da visão: a cor para categorizar os programas; o tamanho dos círculos para representar a quantidade/média; a posição e o movimento que permitiram visualizar a evolução dos dados durante o Triênio de 2013. De acordo com o estatístico John Tukey (1965) ${ }^{8}$ apud Few (2009) uma grande virtude da boa visualização gráfica é que ela pode servir para apresentar de forma clara e eficaz uma mensagem cujo cálculo ou observação pode não ser tão simples, como é o caso do Gráfico 2, em que foram necessários alguns cálculos que estão por trás das representações.

Ao analisar o Gráfico 2, é possível identificar que os dois programas da Unicamp se destacam com relação a quantidade de teses e dissertações defendidas, junto como o programa da USP, ou seja, curiosamente dentre os programas analisados, as instituições que apresentam alto índice de endogenia também são os que mais formaram doutores no Triênio de 2013. Ao analisar especificamente o Programa de Desenvolvimento Econômico da Unicamp, é possível notar que o mesmo é líder na formação tanto de mestres como doutores, no entanto, embora essa liderança seja reconhecida pela Capes na ficha de avaliação, há também um alerta de que o programa apresenta um alto índice de endogenia, sendo que é recomendado que o programa incorpore em suas futuras contratações docentes com origem de formação mais diversificada.

8 Tukey, J. W; M. B. Wilk, Proceedings of the Symposium on Information Processing in Sight Sensory Systems. Pasadena CA: California Institute of Technology, 1965.

\begin{tabular}{l|l|l|l|l|l}
\hline (C) RDBCI: Rev. Digit. Bibliotecon. Cienc. Inf. & Campinas, SP & v.15 & n.2 & p. 324-348 & maio/ago. 2017 \\
\hline
\end{tabular}


Em casos assim, é importante realizar uma análise mais aprofundada, pois de acordo com Faria (2011) a elaboração e o emprego de indicadores dependem fortemente do contexto focalizado e dos propósitos almejados, portanto, é fundamental a realização de estudos que considerem a incorporação das especificidades e interesses daquilo que se está analisando. No mais, além da quantidade de mestres e doutores formados, Moreira e Velho (2008) levantam também a questão relacionada à qualidade e não só quantidade de pesquisas, que é o grande desafio para aqueles que criam as políticas de C\&T: repensar a formação de recursos humanos para criar mecanismos e estabelecer um forte vínculo entre pesquisas com a realidade e necessidades do país.

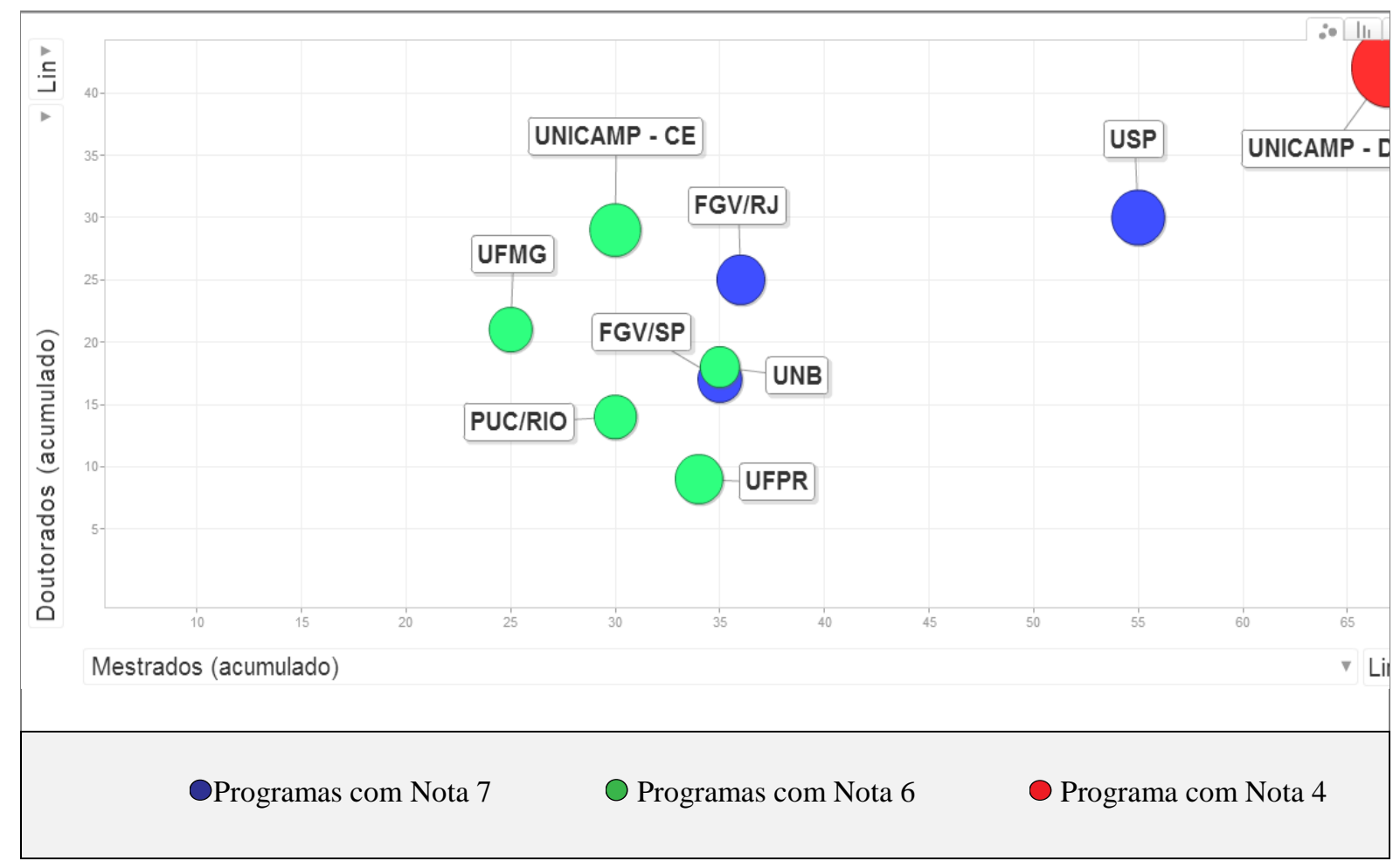

Gráfico 2 - Teses e dissertações concluídas - triênio - G9

Nota: O tamanho do círculo representa a média de orientações concluídas por docente permanente no triênio

Fonte: Elaborado pelos autores a partir das informações disponíveis nos Cadernos de Indicadores de 2010, 2011 e 2012 “TE - Teses e Dissertações” (CAPES, 2010) e da Planilha de Indicadores (Capes, 2014).

\subsection{Produção intelectual}

O quesito produção intelectual é o que tem mais peso no momento da avaliação na área de economia. Segundo do documento da área este quesito é avaliado de acordo com a produção per capita dos docentes permanentes em relação à produtividade média da área, ponderada pela qualidade dos veículos de publicação Capes (2013). Ocorre que são muitos dados e estão dispostos em uma planilha do Microsoft Excel. Como a compreensão desses dados na planilha fica comprometida devido à grande quantidade de informações, optou-se por analisar o

\begin{tabular}{l|l|l|l|l|l}
\hline (C) RDBCI: Rev. Digit. Bibliotecon. Cienc. Inf. & Campinas, SP & v.15 & n.2 & p. 324-348 & maio/ago. 2017 \\
\hline
\end{tabular}


comportamento dos programas com relação a quantidade de artigos publicados em periódicos técnico-científicos aferidos pelo Qualis-Capes, através do gráfico de colunas, que é muito comum e ao mesmo tempo permite utilizar vários tipos de dados ( YAU, 2012). Ele é utilizado, por exemplo, para comparar itens ou mostrar alterações de dados em um período de tempo. Há diversas variações desse tipo de gráfico e a que apresentamos no Gráfico 3 é uma delas.

No Gráfico 3 foi utilizado como regra da visão o comprimento das colunas que indica quantidade e a cor para categorizar os programas. No mais, ele possibilita ter uma visão geral, e ao mesmo tempo analisar cada programa individualmente com relação as publicações por extrato Qualis-Capes. Para Few (2009) ter uma visão geral é muito importante, ela reduz o tempo de busca, permite a detecção de padrões globais, pois, geralmente a heurística da visualização começa com uma visão geral.

Ao analisar o Gráfico 3, observa-se um padrão de comportamento: os programas que possuem nota mais alta (nota 7) são os que possuem mais publicações em periódicos de extratos Qualis-Capes superiores, ao passo que o comportamento do programa com a menor nota (nota 4) é o inverso, isto é, apresenta mais publicações em extratos Qualis-Capes inferiores. No caso do programa com nota 4, é importante analisar de forma mais profunda este indicador, considerando a especificidade do programa, já que se trata de um programa mais voltado para as questões de desenvolvimento nacional.Com relação aos programas com nota 6 não foi possível identificar nenhum padrão de comportamento, no entanto, o programa da PUC-Rio destaca-se ao apresentar uma quantidade total de publicações menor que os demais, no entanto, suas poucas publicações estão concentradas em extratos superiores, o que lhe garante a nota 6 . Portanto, identifica-se um programa que optou pela qualidade (aferida pelo Qualis-Capes) ao invés da quantidade. Este indicador vai ao encontro do Documento de Área (CAPES, 2013) que aponta que o grau de internacionalizações dos programas resulta, principalmente, das publicações em periódicos internacionais, identificadas no Qualis-Capes com as classificações A1 e A2. 


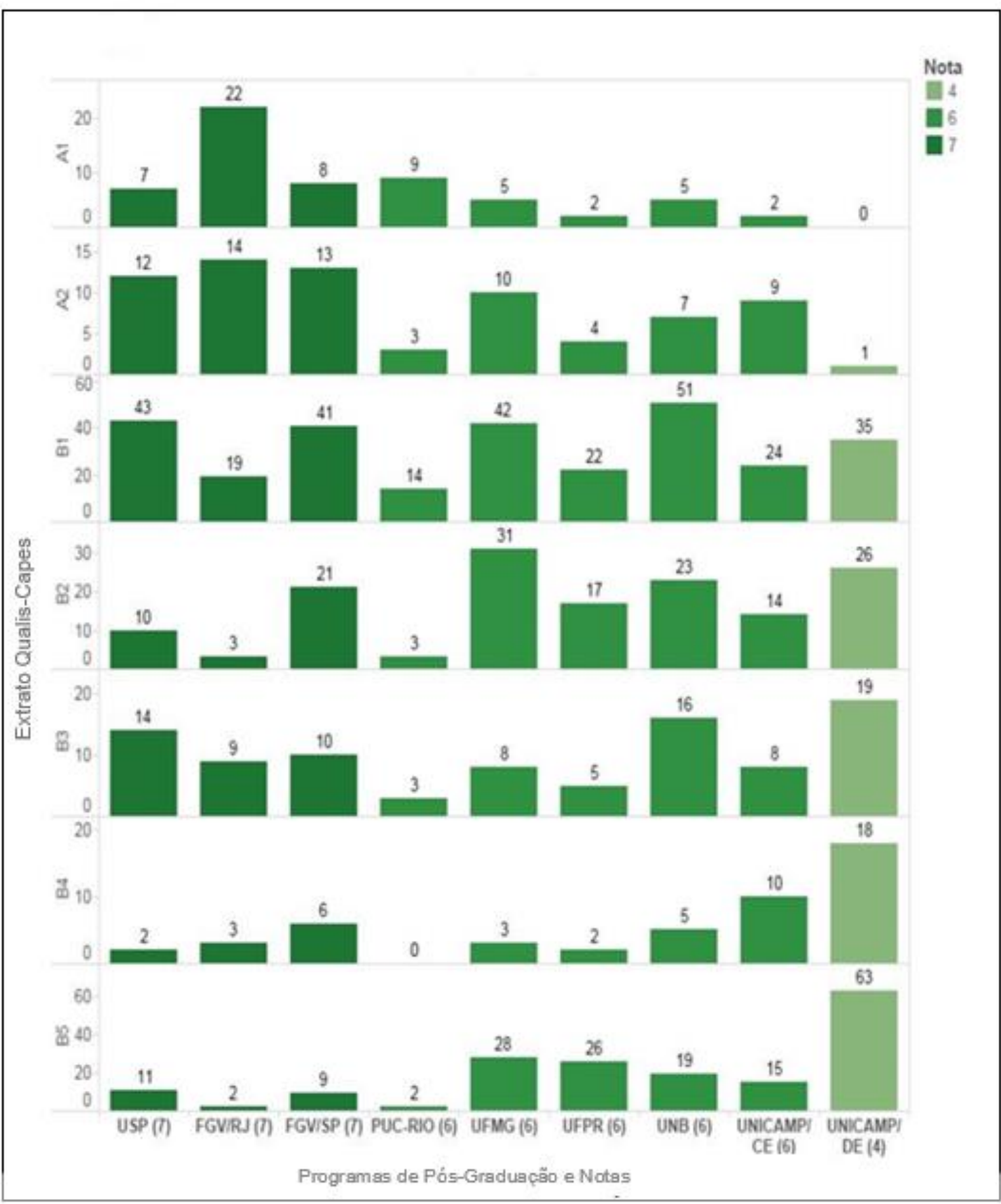

Gráfico 3 - Quantidade de artigos publicados em periódicos técnico-científicos nos estratos Qualis (A1-B5)

Fonte: Elaborado pelos autores a partir das informações disponíveis na Planilha de Indicadores (CAPES, 2014). 


\section{CONSIDERAÇOES FINAIS}

A presente pesquisa elaborou e analisou um conjunto de indicadores científicos, com base na área da visualização de informação, com o intuito de maximizar a compreensão sobre as dinâmicas da ciência, em especial sobre as informações disponibilizadas pelo Sistema de Avaliação da Capes sobre o desempenho dos PPG, com as informações disponíveis nos Cadernos e Planilhas de Indicadores da Capes. E de forma mais específica, estabeleceu as melhores práticas na visualização da ciência, analisando os indicadores de desempenho dos PPG, e por fim apresenta os resultados alcançados e discutidos.

Sobre as melhores práticas em visualização de informação foi identificado e aplicado, no contexto das dinâmicas científicas, um conjunto de regras: cor, posição, comprimento, movimento, largura, tamanho e forma, e assim, foi selecionada diferentes ferramentas, na forma de gráficos, para maximizar a compreensão dos indicadores científicos sobre o desempenho dos PPG, com base nos dados advindos dos Cadernos de Indicadores e da Planilha de Indicadores, resultado da avaliação da Trienal 2013 da Capes.

Com relação às dimensões da avaliação, no quesito corpo docente, dentre os PPG analisados, a endogenia aparece fortemente relacionada aos dois PPG da Unicamp, que também são os que mais formam doutores e mestres juntos com a USP, o que sugere a necessidade de um aprofundamento no tema, para tentar compreender se há relação entre esses dois indicadores. Com relação a produção intelectual, os PPG com nota 7 são os que mais publicam em periódicos com maiores Qualis-Capes A1 a A2, ao passo que em periódicos Qualis-Capes B5 a ordem é inversa. Os resultados reforçam que os critérios do Sistema de Avaliação da Capes tende a premiar os PPG com mais publicações internacionais uma vez que o peso deste requisito no Sistema apara a área de Economia é maior.

Com base no referencial teórico e na discussão dos resultados alcançados, conclui-se que é viável fazer uso dos conceitos da área de visualização de informação, para facilitar a compreensão das dinâmicas da ciência, em especial sobre a atuação dos Programas de PósGraduação, por intermédio da elaboração de indicadores a partir dos dados e informações disponibilizados pelo Sistema de Avaliação da Capes, auxiliando os tomadores de decisão a respeito da implementação de políticas públicas e na gestão dos PPG.

\section{REFERÊNCIAS}

ALVES, Camila. A infografia como fator de influência na compreensão de temos de C\&T. In: CONGRESSO DE CIÊNCIAS DA COMUNICAÇÃO NA REGIÃO SUL, 11., 2010, Novo Hamburgo. Anais do... Novo Hamburgo: Intercom, 2010. Disponível em: <http://www.intercom.org.br/sis/2013/resumos/R8-0995-1.pdf> . Acesso em: 2 nov. 2014.

BAUMGARTEN, Maíra. Avaliação e gestão de ciência e tecnologia: Estado e coletividade científica. Revista Crítica de Ciências Sociais, Coimbra, n. 70, 2004. Disponível em:

\begin{tabular}{l|l|l|l|l|l|l}
\hline (C) RDBCI: Rev. Digit. Bibliotecon. Cienc. Inf. & Campinas, SP & v.15 & n.2 & p. 324-348 & maio/ago. 2017 \\
\hline
\end{tabular}


〈http://rccs.revues.org/1046>. Acesso em: 26 jun. 2014.

BOMENY, Helena. Um personagem e suas histórias. Cienc. Cult., São Paulo, v. 66, n. 4, Dec. 2014.

BRAGA, Mariana Moron Saes; VENTURINI, Ana Elisa João Francisco. Endogenia acadêmica em um programa de pós-graduaçao em direito. In: MEZZAROBA, Orides; TAVARES NETO, José Querino; VASCONCELOS, Silvia Andréia (Coord.). Direito, educação, ensino e metodologia jurídicos. Florianópolis: FUNJAB, 2013. p. 91-108 Disponível em: 〈http://www.publicadireito.com.br/artigos/?cod=30f0641c041f03d9>. Acesso em: 9 fev. 2015.

BRASIL. Ministério da Educação. Coleta de dados - conceitos e orientaçoes: manual de preenchimento da Plataforma Sucupira. Brasília: Capes, 2014. Disponível em: $<$ https://sucupira.capes.gov.br/sucupira/public/lancamento/manual.jsf;jsessionid=g4CA8Ju0 mDU1EsElt776TWeb.sucupira-75>. Acesso em: 28 out. 2014.

BRASIL.Ministério da Educação. Pós Stricto Sensu. 2016. Disponível em: <http://portal.mec.gov.br/pos-graduacao/pos-graduacao〉. Acesso em: 26 de Jun. 2016.

BRASIL. Ministério da Educação. Coordenação de Aperfeiçoamento de Pessoal de Nível Superior (CAPES). Caderno de Indicadores. Brasília: Capes, 2010. Disponível em: $<$ http://conteudoweb.capes.gov.br/conteudoweb/CadernoAvaliacaoServlet $>$. Acesso em: 10 mar. 2012.

BRASIL. Ministério da Educação. Coordenação de Aperfeiçoamento de Pessoal de Nível Superior (CAPES). Documento de área 2013. Brasília: Capes 2013. Disponível em: < https://www.capes.gov.br/images/stories/download/avaliacaotrienal/Docs_de_area/Economia _doc_area_e_comiss\%C3\%A3o_16out.pdf >. Acesso em: 10 mar. 2012.

BRASIL. Ministério da Educação. Coordenação de Aperfeiçoamento de Pessoal de Nível Superior (CAPES). Planilha de indicadores. Brasília: Capes, 2014. Disponível em: $\langle$ http://www.avaliacaotrienal2013.capes.gov.br/resultados/planilhas-comparativas $>$. Acesso em 26 jun. 2016.

BRASIL. Ministério da Educação. Coordenação de Aperfeiçoamento de Pessoal de Nível Superior (CAPES). Resultado Trienal-2013. Brasília: Capes, 2015. Disponível em: <http://www.avaliacaotrienal2013.capes.gov.br/>. Acesso em: 12 mar. 2015.

DANTAS, Flávio. Responsabilidade social e pós-graduação no Brasil: idéias para (avali) ação. Revista Brasileira de Pós-Graduação, Brasília, v. 1, n. 2, 2004. Disponível em: <http://ojs.rbpg.capes.gov.br/index.php/rbpg/article/view/46>. Acesso em: 29 out. 2014.

DAVYT, Amilcar; VELHO, Léa. A avaliação da ciência e a revisão por pares: passado e presente. Como será o futuro? História, Ciências, Saúde-Manguinhos, Rio de Janeiro, v. 7, n. 1, p. 93-116, 2000.

DORTA-GONZÁLEZ, Pablo; DORTA-GONZÁLEZ, María Isabel. Indicador bibliométrico

\begin{tabular}{l|l|l|l|l|l|l}
\hline (C) RDBCI: Rev. Digit. Bibliotecon. Cienc. Inf. & Campinas, SP & v.15 & n.2 & p. 324-348 & maio/ago. 2017 \\
\hline
\end{tabular}


basado en el índice h. Revista Española de Documentación Científica, Espanha, v. 33, n. 2, 2010. Disponível em: <http://redc.revistas.csic.es/index.php/redc/article/view/553/627>. Acesso em: 7 abr. 2014.

FARIA, Leandro Innocentini Lopes de; et al. Análise da produção científica a partir de publicações em periódicos especializados. In: BRETANI, Ricardo Renzo; CRUZ, Carlos Henrique de Brito (Eds.). Indicadores de ciência, tecnologia e inovação em São Paulo2010. São Paulo: Fapesp, 2011.

FEW, Stephen. Simple visualization techniques for quantitative analysis. California: Analytics Press, 2009.

FREITAS, Carla Maria dal Sasso; et al. Introdução à visualização de informações. RITA, Porto Alegre, v. 8, n. 2, 2001.

GREGOLIN, José Angelo Rodrigues et al. Análise da produção científica a partir de indicadores bibliométricos. In: LANDI, Francisco Romeu; GUSMÃO, Regina. (Coord.). Indicadores de ciência, Tecnologia e Inovação em São Paulo-2004. São Paulo: Fapesp, 2005. p. 5-43, cap. 5, v.1. Disponível em: < http://www.fapesp.br/indicadores2004/volume1 las_iniciais_voll.pdf> Acesso em: 7 abr. 2014.

HORTA, José Silvério Baía; MORAES, Maria Célia Marcondes de. O sistema CAPES de avaliação da pós-graduação: da área de educação à grande área de ciências humanas. Rev. Bras. Educ., Rio de Janeiro, n. 30, p. 95-116, dez. 2005 . Disponível em $<$ http://www.scielo.br/scielo.php?script=sci_arttext\&pid=S1413-24782005000300008 \&lng=pt\&nrm=iso >. Acesso em: 7 abr. 2014.

HORTA, Hugo. Deepening our understanding of academic inbreeding effects on research information exchange and scientific output: new insights for academic based research.

Higher Education, Netherlands, v. 65, n. 4, 2012.

HORTALE, Virginia Alonso. Modelo de avaliação Capes: desejável e necessário, porém, incompleto. Cad. Saúde Pública, Rio de Janeiro, v. 19, n. 6, 2003. Disponível em: < http://www.scielo.br/pdf/csp/v19n6/a27v19n6.pdf> Acesso em: 7 abr. 2014.

LIBERAL, Claudemir. Gonçalves. Indicadores de ciência e tecnologia: conceitos e elementos históricos 1. Ciência \& Opnião, Curitiba, v. 2, n. 1/2, 2005.

MARCONI, Marina de Andrade; LAKATOS, Eva Maria. Fundamentos de metodologia científica. 7. ed. São Paulo: Atlas, 2010.

MODOLO, Cristiane Machado. Infográficos: características, conceitos e princípios básicos. In: CONGRESSO BRASILEIRO DE CIÊNCIAS DA COMUNICAÇÃO DA REGIÃO SUDESTE, 12., 2007, Juiz de Fora, Anais... Juiz de Fora: Intercom, 2007. Disponível em: <http://ddiprojeto2.xpg.uol.com.br/infograficos_caracteristicas_conceitos_e_principios_basic os.pdf $>$. Acesso em: 16 maio 2015.

\begin{tabular}{c|c|c|c|c|c}
\hline (C) RDBCI: Rev. Digit. Bibliotecon. Cienc. Inf. & Campinas, SP & v.15 & n.2 & p. 324-348 & maio/ago. 2017 \\
\hline
\end{tabular}


MOREIRA, Maria Lígia.; VELHO, Léa. Pós-graduação no Brasil: da concepção “ofertista linear" para "novos modos de produção do conhecimento" implicações para avaliação. Avaliação: Revista da Avaliação da Educação Superior, Campinas, v. 13, n. 3, 2008.

NATIONAL Science Foundation. Disponível em: <http://www.nsf.gov/>. Acesso em: 22 nov. 2014.

OKUBO, Yoshiko. Bibliometric indicators and analysis of research systems: methods and examples. OECD - Science, technology and industry working papers, Paris, n. 1997/01, 70 p., Jan.1997. Disponível em: <http://ideas.repec.org/p/oec/stiaaa/1997-1-en.html>. Acesso em: 9 mar. 2014.

PAINEL Lattes. Disponível em: < http://estatico.cnpq.br/painelLattes/>. Acesso em: 27 de jul. 2016

PACIEVITCH, Th'ais. Coordenação de Aperfeiçoamento de Pessoal de Nível Superior CAPES. 2016. Disponível em: <http://www.infoescola.com/educacao/coordenacao-deaperfeicoamento-de-pessoal-de-nivel-superior-capes/>. Acesso em 26 de Jun. 2016.

PRESSER, Nadi Helena; SILVA, Eli Lopes da; SANTOS, Raimundo Nonato Macedo dos. Resources to formulate and to visualize indicators to support processes of educational management in hegher education institutes. Revista Digital de Biblioteconomia e Ciência da Informação, Campinas, v. 7, n. 2, 2010.

SCHMITT, Valdenise. A infografia jornalistica na ciência e tecnologia. 2006. 105 f. Dissertação (Mestrado em Engenharia e Gestão do Conhecimento) - Faculdade de Engenharia e Gestão do Conhecimento, Universidade Federal de Santa Catarina, Florianópolis, SC, 2006. Disponível em: < http://www.bocc.ubi.pt/pag/schmitt-valdeniseinfografia-jornalistica.pdf>. Acesso em: 2 nov. 2014.

SCHWARTZMAN, Simon. Uses and abuses of education assessment in Brazil. Prospects, Netherlands, v. 43, n. 3, 2013. Disponível em: <http://link.springer.com/10.1007/s11125-0139275-9>.

SCIMAGO research group. 2011. Disponível em: <http://www.excelencia.universia.net/ scimago/pt/scimago.jsp >. Acesso em: 15 dez. 2014.

SILVA, Celmar Guimarães da. Exploração de bases de dados de ambientes de educação a distância por meio de ferramentas de consulta apoiadas por visualização de informação. 2006. Tese (Doutorado em Ciência da Computação) - Instituto de Computação, Universidade Estadual de Campinas, Campinas, SP, 2006.

SOARES, Maria Susana Arrosa (Coord.). A educação superior no brasil. Brasília: Capes, 2002. 304p. ISBN 8588468093.

MEIJIA TRUJILLO, Albeiro. Desenvolvimento, aprimoramento e consolidação de uma educação nacional de qualidade. Brasília: Unesco, 2013. Disponível em:

\begin{tabular}{c|c|c|c|c|c}
\hline (C) RDBCI: Rev. Digit. Bibliotecon. Cienc. Inf. & Campinas, SP & v.15 & n.2 & p. 324-348 & maio/ago. 2017 \\
\hline
\end{tabular}


<http://www.catedra.uevora.pt/unesco/index.php/unesco_pt/content/download/881/5575/file/ Acordo.pdf $>$. Acesso em: 26 out. 2014.

VLAB4U: Grupo de Pesquisa de Informação. Disponível em: <http://vlab4u.info/. Acesso em 27 jul. 2016

VOLPATO, Gilson Luiz. Metodo lógico para a redação científica. Botucatu: Best Writhing, 2011.

YAU, Nathan. Visualise isto: o guia do flowingdata para design, visualização e estatística. Rio de Janeiro: Alta Books, 2012.

ZACKIEWICZ, Mauro. Coordenação e organização da inovação: perspectivas do estudo do futuro e da avaliação em ciência e tecnologia. Parcerias Estratégicas, Brasília, n. 17, 2003. Disponível em: <http://seer.cgee.org.br/index.php/parcerias_estrategicas/article/viewArticle/ 242>. Acesso em: 25 abril 2015.
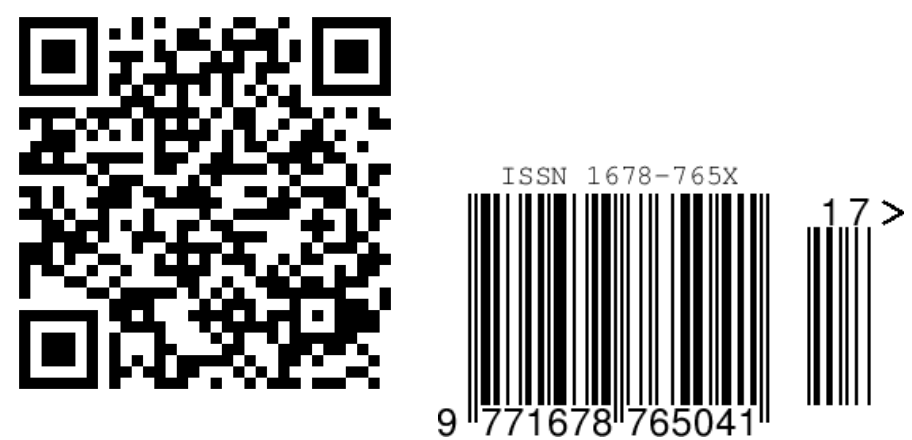